\title{
Health of vermiculite miners exposed to trace amounts of fibrous tremolite
}

\author{
J C McDONALD, A D McDONALD, P SÉBASTIEN, K MOY \\ From the School of Occupational Health, McGill University, Montreal, Quebec, Canada
}

\begin{abstract}
A small cohort of 194 men with low exposure to fibrous tremolite (mean $0.75 \mathrm{f} / \mathrm{ml} \mathrm{y}$ ) in the mining and milling of vermiculite in South Carolina experienced 51 deaths 15 years or more from first employment. The SMR (all causes) was $1 \cdot 17$ reflecting excess deaths from circulatory disease. There were four deaths from lung cancer and 3.31 expected (SMR 1.21, 95\% CI 0.33-3.09). Three of the four deaths were in the lowest exposure category $(<1 \mathrm{f} / \mathrm{ml} \mathrm{y})$; no death was attributed to mesothelioma or pneumoconiosis. These findings contrast with those in Montana where the vermiculite ore was heavily contaminated with fibrous tremolite. A radiographic survey of 86 current and recent South Carolina employees found four with small parenchymal opacities $(\geqslant 1 / 0)$ and seven with pleural thickening. These proportions were not higher than in a non-exposed group and much lower than had been observed in Montana. Examination of sputum from 76 current employees showed that only two specimens contained typical ferruginous bodies, confirming low cumulative fibre exposure. Any possible adverse effects of work with vermiculite, minimally contaminated with fibrous or non-fibrous tremolite, were thus beyond the limits of detection in this workforce.
\end{abstract}

A cohort study of mortality of vermiculite miners in Libby, Montana, and a radiological survey of past and present employees in the same mine were made in $1983-4 .^{1-3}$ The Montana deposit was heavily contaminated by asbestiform fibre in the tremolite series. Dry milling operations, before the introduction of ventilation equipment in 1965 , had entailed exposure levels in excess of $100 \mathrm{f} / \mathrm{ml}$ and, until a new wet mill was built in 1974, of levels of around $20 \mathrm{f} / \mathrm{ml}$. The epidemiological results showed a substantially increased risk of lung cancer (about $1 \%$ per fibre year of exposure), malignant mesothelioma (proportional mortality $2 \cdot 4 \%$ ), and of pleural and parenchymal change on $x$ ray examination. Whereas it was thought that adverse effects attributable to exposure to tremolite would not be detectable at present day levels $(0.1 \mathrm{f} / \mathrm{ml})$ in Libby, confirmation of this belief was clearly desirable. Thus the existence in South Carolina of vermiculite production from deposits, believed to be virtually free of fibrous tremolite, warranted the research reported in this paper.

Accepted 14 August 1987

\section{Materials and methods}

\section{WORKPLACE DESCRIPTION}

Vermiculite in the Enoree region (South Carolina) occurs in small surface deposits, some 50 of which have been quarried by the company since 1946 . Owing to the climate and presence of clay in the mineral deposits, the quarries are usually wet, although the roads may be dry and dusty in the summer. Two main types of ore, locally called "Waldrep" and "Allen," are recognised, the former a hydrobiotite and the latter a poorer quality vermiculite. Use of Allen ore which started in 1966 has increased over the years but never exceeded $33 \%$.

The first part of the milling process is wet but after drying the ore is fed to the top of a screening tower where it is sized. The concentrate is then conveyed to storage silos and bins before being bagged or loaded into railcars. Current annual production is around 100000 tons. The number of employees reached about 80 in the 1960s and has not changed much since then.

Appreciable exposure to dust is confined to operations with dried material in the screening tower, storage area, and bagging station. Efforts to reduce dust in the screening tower began in 1970 with the installation of a ventilation system. At the same time 
the bagging station was transferred from the storage silo to a ventilated building equipped with source collectors. Personal protection was required when loading cars or moving concentrate in the storage areas.

Fourteen air samples for respirable dust (eight hour personal sampling with cyclone and cassette) were taken in the period 1980-5 on workers exposed to dry concentrate. Gravimetric concentrations of respirable dust ranged from 0.15 to $1.17 \mathrm{mg} / \mathrm{m}^{3}$ (median 0.26 $\mathrm{mg} / \mathrm{m}^{3}$ ). Quartz content in these samples ranged from nil to $10 \%$. Size selective sampling carried out in 1986 with a CIP 10 dust sampler showed that $4 \%$ of the dust by weight was in the respirable range. ${ }^{4}$

\section{DUST EXPOSURE}

In December 1985 and May 1986, 21 bulk samples from dust were collected on the structural beams in the tower and silo. As fibrous particles were of concern, the samples were analysed by phase contrast microscopy (PCM) and analytical transmission electron microscopy (ATEM). For optical analysis, fibres were counted at $500 \times$ using the criteria of the NIOSH reference method $7400 \mathrm{a}$ for asbestos. A mean concentration of $0.27( \pm 0.07)$ PCM fibres per milligram of dust was found with mean length $20.4 \mu \mathrm{m}$ and diameter $2 \cdot 3 \mu \mathrm{m}$. Four types of elongated particles were identified by electron microscopy and energy dispersive $x$ ray spectrometry (EDSX) ${ }^{5}$ tremoliteactinolite $(37.9 \%)$, vermiculite fragments $(28.0 \%)$, talc/anthophyllite $(15.9 \%)$, and iron rich fibres $(4.6 \%) ; 14 \%$ of the fibres could not be identified.

In September 1986, 58 static air samples were taken in 10 areas on membrane filters (Millipore MF, $37 \mathrm{~mm}$ cassette, $0.8 \mu \mathrm{m}$ pore size). Fibres were first counted by PCM using the NIOSH reference method and then identified and sized by ATEM. ${ }^{6}$ In preparation for electron microscopical analysis, samples were kept

Table 1 Mean concentrations ( $f / c c)$ of airborne fibres measured by phase contrast microscopy and analytical electron microscopy. Fifty eight air samples were taken in 10 zones (number of fibres counted in parentheses)

\begin{tabular}{lrlr}
\hline & No & ATEM & \multicolumn{1}{l}{$P C M$} \\
\hline Screening tower & 8 & $0.317(18)^{*}$ & $0.031(11)$ \\
Railcar loadout area & 10 & $0.105(7)$ & $0.007(3)$ \\
Storage silo & 6 & $0.105(7)$ & $0.007(3)$ \\
Drier area & 9 & $0.063(30)$ & $0.005(2)$ \\
Main research laboratory & 1 & $0.038(14)$ & $<0.002(0)$ \\
Mill shop & 3 & $0.036(19)$ & $<0.002(0)$ \\
Bagging area & 5 & $0.028(15)$ & $0.006(3)$ \\
Mine shop & 6 & $0.027(14)$ & $<0.002(0)$ \\
Ore truck cab & 6 & $0.021(11)$ & $0.002(1)$ \\
Wet mill & 4 & $0.010(5)$ & $<0.002(0)$ \\
\hline
\end{tabular}

ATEM = Analytical transmission electron microscopy.

PCM = Phase contrast microscopy.

No $=$ Number of air samples on membrane filter.
Table 2 Mean concentrations $(f / c c)$ of airborne fibres measured by the membrane filter method

\begin{tabular}{lllll}
\hline & $1970-$ & $1975-$ & $1980-$ & $1985-$ \\
\hline Wet zone & $\begin{array}{l}0 \cdot 14(0 \cdot 00)^{*} \\
(\mathrm{n}=8)\end{array}$ & $\begin{array}{l}0 \cdot 21(0 \cdot 38) \\
(\mathrm{n}=13)\end{array}$ & $\begin{array}{l}0 \cdot 05(0 \cdot 10) \\
(\mathrm{n}=18)\end{array}$ & $\begin{array}{l}0 \cdot 00(0 \cdot 00) \\
(\mathrm{n}=16)\end{array}$ \\
Dry zone & $\begin{array}{l}0 \cdot 84(2 \cdot 40) \\
(\mathrm{n}=27) \dagger\end{array}$ & $\begin{array}{l}0 \cdot 52(1 \cdot 01) \\
(\mathrm{n}=78)\end{array}$ & $\begin{array}{l}0 \cdot 11(0 \cdot 22) \\
(\mathrm{n}=38)\end{array}$ & $\begin{array}{l}0 \cdot 02(0.04) \\
(\mathrm{n}=76)\end{array}$ \\
\hline
\end{tabular}

*90th percentile of the distribution of concentrations in $\mathrm{f} / \mathrm{cc}$. tIncluding two measurements in 1969.

overnight in a low temperature plasma asher, the ashes suspended in water, deposited on a Nuclepore polycarbonate membrane and transferred on to ATEM grids using a carbon replica technique. Grids were observed in the transmission mode at $10000 \times$ magnification to analyse fibres longer than 5 microns. Each fibre encountered was sized (length and diameter) and identified by EDSX on the basis of its elemental chemistry. A sufficient number of grid openings was scanned to achieve a detection limit of $0.002 \mathrm{f} / \mathrm{cc}$.

Mean PCM fibre concentrations are reported in table 1; all but one were below $0.01 \mathrm{f} / \mathrm{cc}$. With ATEM, counts were higher and mean concentrations ranged from 0.01 to $0.32 \mathrm{f}>5 \mu \mathrm{m} / \mathrm{cc}$. Both ATEM and PCM analyses identified the screening tower as the most dusty area. As in the settled dust, four types of fibres were identified by EDSX in the air samples: tremoliteactinolite $(47.6 \%)$, iron rich fibres $(23 \%)$, vermiculite fragments $(7 \cdot 9 \%)$, and talc anthophyllite $(4.8 \%)$; $16.7 \%$ could not be identified. The airborne fibres were on average thinner $(1.1 \mu \mathrm{m})$ and shorter $(12.7 \mu \mathrm{m})$ than those in the bulk sample.

Dates of start and termination of jobs at the company were available for all 248 individuals in the study, including 193 who met the cohort criteria. Forty two job titles were identified, 13 for management and clerical staff, six for miners, 13 for millers, and 10 for technicians and personnel in services and supplies. Five had also worked either in the Montana mine or in an expanding plant that processed concentrate from Montana as well as South Carolina.

To be consistent with the previous study in Montana, a method was designed that took maximum advantage of existing air measurements. Since 1969, 274 air fibre measurements had been made, 125 by the Mine Safety and Health Administration and the rest by the company. The mean sampling time in the mill increased from 27 minutes before 1975 to 71 minutes in 1984-5. Personal samples were of longer duration than static samples but too short to reflect complete shift exposure. Some individuals, such as office workers or prospectors, had little exposure to dust. For production workers, two exposure zones were defined, a "wet zone" for operations before drying and a "dry zone" 
Table 3 Estimates of exposure intensity $(f / c c)$ by zones and calendar years

\begin{tabular}{llllll}
\hline & $<1970$ & $1970-$ & $1975-$ & $1980-$ & $1985-$ \\
\hline No special exposure & 0.00 & 0.00 & 0.00 & 0.00 & 0.00 \\
Wet zone & 0.09 & 0.14 & 0.21 & 0.05 & 0.00 \\
Dry zone (average) & 0.84 & 0.84 & 0.52 & 0.11 & 0.02 \\
Dry zone (peak) & 2.40 & 2.40 & 1.01 & 0.22 & 0.04 \\
\hline
\end{tabular}

for the screening and storage areas and the bagging station. Mean fibre concentrations by zone and quinquennia are reported in table 2 . Overall, concentrations were low; $5.7 \mathrm{f} / \mathrm{cc}$ being the highest ever measured at Enoree.

Variations with time in the wet zone (table 2) were not considered important and the overall average concentration $(0.09 \mathrm{f} / \mathrm{cc})$ was used for years before 1970. Mean concentrations in the dry zone gradually decreased after 1970 , probably due to the installation of ventilation equipment; the mean concentrations for the quinquennium 1970-4 were used for the earlier years. Discussion with a senior manager who had spent his entire career at Enoree indicated that work in the dry zone entailed peaks of exposure. Air samples were inadequate to describe these peak exposures, therefore the 90th percentiles of the concentration distributions (table 2) were used as surrogates.

Estimates of exposure intensity by zone and calendar year are shown in table 3 . The proportion of the total working time spent in each zone was estimated after review of work histories by the senior manager. Periods of time were identified in which employment was within the same exposure zone and this period multiplied by the appropriate fibre concentration to give cumulative exposure estimates $(\mathrm{f} / \mathrm{ml} \mathrm{y})$ for each employee.

\section{COHORT MORTALITY STUDY}

The cohort comprised all 194 men ever employed by the company in South Carolina for six months or more who had been hired before 1 January 1971 . The vital status as of 1 January 1986 of 189 men was established by local inquiries, giving a minimum latency of 15 years. The remaining five men could be traced only through social security files. It was ascertained that they were alive in 1984; they were therefore included in the man-years analysis only until 1 July of that year. Criteria for inclusion in the cohort were thus less demanding than at Libby where at least one year of employment and 20 years latency were required; this was to increase the size of the study group, though with some loss in comparability.

Altogether, 51 members of the cohort were reported dead; death certificates were obtained for them all. The registered causes of death were coded by a qualified nosologist (the same person who had coded the certificates in the Montana study) according to the eighth revision of the International Classification of Diseases.

\section{RADIOLOGY}

On 1 April 1986 the company had 80 employees of whom eight had been hired after the last annual health examination and chest $x$ ray examination during the summer of 1985. Films were obtained for 68 of the 72 examined at that time; these were supplemented with 15 routine annual films taken in 1983 or 1984 from exemployees no longer present in 1985, making a total of 83. In addition to this series we obtained (a) 25 films taken with the same machine from employees in another division of the company, not believed to have been exposed to dust, and $(b) 25$ films from the Montana mine selected at random from men with and without parenchymal small opacities $(<1 / 0)$. The complete set of 133 films, in random order, was assessed blind and independently on the ILO 1980 classification by the same three experienced readers as for the Montana survey. Of the four employees whose films were not obtained in time for the assessment, two had films read in 1984, and another in 1986, by one or more "B" readers using the ILO 1980 classification; these results were included in our analysis. The one remaining male employee had no recent routine annual film because of long term treatment for leukaemia.

\section{SPUTUM STUDY}

In May 1986 sputum specimens were collected from 76 current workers. Each worker was given three large mouthed plastic cups containing $70 \%$ ethanol and was asked to collect at home his "wake-up sputum" on three consecutive days. Specimens of day 1 and 3 were blended, centrifuged, and the volume of the pellet recorded. Cellularity was assessed by counting the number of macrophages in an aliquot of the pellet. The rest was digested and then filtered in order to count the typical and atypical ferruginous bodies by light microscopy at $300 \times$ magnification. The methods for this part of the investigation were the same as those used in Montana.?

\section{STATISTICAL ANALYSIS}

The mortality of the cohort was compared with that of white and black men in the US using the person-years at risk method to compute the expected number of deaths and hence standardised mortality ratios (SMRs). The computations were made using Monson's computer program. ${ }^{8}$ No comparison was made with South Carolina rates as, for respiratory cancer, these were close to those for the United States.

Radiographic readings from the three readers were combined as a median score. The prevalence of 
Table 4 Descriptive statistics for cohort study $(n=194)$

\begin{tabular}{lccr}
\hline Year of birth & \multicolumn{3}{c}{ Year of hire } \\
\hline-1899 & 5 & -1949 & 13 \\
$1900-1909$ & 10 & $1950-1959$ & 86 \\
$1910-1919$ & 29 & $1960-1969$ & 87 \\
$1920-1929$ & 61 & $1970-1974$ & 8 \\
$1930-1939$ & 46 & & \\
$1940-$ & 43 & \\
\multicolumn{5}{c}{ Cumulative exposure at end of service $(\mathrm{f} / \mathrm{ml}$ y) } \\
$<1$ & 103 \\
$1-<10$ & 83 & & \\
$\geqslant 10$ & 8 &
\end{tabular}

abnormalities and the mean cumulative exposure were tabulated in three age groups $(20-39,40-59, \geqslant 60)$.

\section{Results}

\section{MORTALITY}

Descriptive statistics for the 193 men in the cohort are reported in table 4. The first workers were hired in 1946. On 1 January 1986 the mean duration of employment was $9 \cdot 2$ years and the cohort accumulated a total of 1817 man-years of exposure. Fifty three per cent of the cohort members had less than $1 \mathrm{f} / \mathrm{ml}$ y of cumulative exposure, the geometric mean for the whole cohort being $0.75 \mathrm{f} / \mathrm{ml} \mathrm{y}$. For the 51 cohort members reported to be dead, the mean period between start of employment and death was 19.7 years $( \pm 1 \cdot 2)$.

Deaths by age and certified cause are reported in table 5. Four deaths were attributed to respiratory cancer, none to pneumoconiosis. Mortality for all causes was in excess (table 6). This excess, more pronounced in black subjects and mainly due to circulatory disease, did not reach a statistically significant level.

Table 7 gives the distribution of the four deaths from respiratory cancer by cumulative exposure and time since first employment. Three of them occurred at
Table 5 Deaths by age and certified cause

\begin{tabular}{llllll}
\hline \multirow{2}{*}{$\begin{array}{l}\text { Cause of death } \\
\text { (ICD code) }\end{array}$} & \multicolumn{3}{l}{ Age at death $(y)$} & \\
\cline { 2 - 4 } & $<45$ & $45-64$ & $\geqslant 65$ & Total \\
\hline All causes & 10 & 22 & 19 & 51 \\
$\begin{array}{llrlr}\text { Malignant neoplasms: } \\
\quad \text { Respiratory (161-163) }\end{array}$ & - & 3 & 1 & 4 \\
$\begin{array}{l}\text { Abdominal (150-159) } \\
\text { Other (140-149, 160, 164-208) }\end{array}$ & - & 1 & - & - & 1 \\
Circulatory disease (390-458) & 2 & 13 & 12 & 27 \\
Respiratory (460-519) & 1 & 1 & 1 & 3 \\
All other causes & 7 & 4 & 2 & 13 \\
\hline
\end{tabular}

cumulative exposure less than $1 \mathrm{f} / \mathrm{ml}$ y. None occurred in the category of the highest cumulative exposures $(>10 \mathrm{f} / \mathrm{ml} \mathrm{y})$ in which the expectation was low $(0 \cdot 19)$.

\section{RADIOLOGY}

Among the 86 Enoree employees who were examined by $x$ ray (including the three whose films were classified individually), four ( $5 \%$ ) showed small parenchymal opacities scored $\geqslant 1 / 0$ (table 8 ). Only two had a cumulative exposure substantially higher than the mean for the age group. In the non-exposed group of 25 two $(8 \%)$ had small opacities $\geqslant 1 / 0$, a proportion higher than in the Enoree group. The age distribution of the non-exposed group was unknown, however. Second readings of parenchymal changes on the 25 Libby films were overall lower than those reported the first time $(9 v 13$ films with small opacities $\geqslant 1 / 0)$ but were much more frequent than at Enoree.

Similarly, pleural thickening was noted in seven $(8 \%)$ of the Enoree films compared with two $(8 \%)$ in the non-exposed group and $10(40 \%)$ at Libby. No pleural calcification was read at Enoree, one case in the non-exposed group, and two at Libby.

\section{SPUTUM}

Seven of the 76 specimens could not be analysed because of technical difficulties. Among the remaining 69 , nine had atypical ferruginous bodies in sputum with concentrations not exceeding four per pellet and

Table 6 Observed and expected deaths by race and cause (reference: United States white and black men)

\begin{tabular}{|c|c|c|c|c|c|c|c|c|}
\hline \multirow[b]{2}{*}{ Cause of death } & \multicolumn{2}{|c|}{ Blacks } & \multicolumn{2}{|c|}{ Whites } & \multicolumn{4}{|c|}{ Total } \\
\hline & $\bar{o}$ & $E$ & $\bar{O}$ & $E$ & $\bar{O}$ & $E$ & $S M R$ & $(95 \% \mathrm{CI})$ \\
\hline $\begin{array}{l}\text { All causes } \\
\text { Malignant neoplasms: }\end{array}$ & 15 & 10.88 & 36 & $32 \cdot 86$ & 51 & $43 \cdot 74$ & $1 \cdot 17$ & $0 \cdot 87-1 \cdot 51$ \\
\hline $\begin{array}{l}\text { Respiratory } 160-163 \\
\text { Abdominal } 150-159 \\
\text { Other } \\
\text { Circulatory disease } 390-458 \\
\text { Non-malignant respiratory disease }\end{array}$ & $\begin{array}{l}2 \\
1 \\
1 \\
7\end{array}$ & $\begin{array}{l}0 \cdot 78 \\
0 \cdot 64 \\
0 \cdot 74 \\
4 \cdot 58\end{array}$ & $\begin{array}{r}2 \\
0 \\
2 \\
20\end{array}$ & $\begin{array}{r}2 \cdot 53 \\
1 \cdot 79 \\
2 \cdot 61 \\
15 \cdot 90\end{array}$ & $\begin{array}{r}4 \\
1 \\
3 \\
27\end{array}$ & $\begin{array}{r}3 \cdot 31 \\
2 \cdot 43 \\
3 \cdot 35 \\
20 \cdot 48\end{array}$ & $\begin{array}{l}1 \cdot 21 \\
0.41 \\
0.90 \\
1 \cdot 32\end{array}$ & $\begin{array}{l}0.33-3 \cdot 09 \\
0 \cdot 01-2 \cdot 29 \\
0 \cdot 18-2 \cdot 62 \\
0 \cdot 87-1.92\end{array}$ \\
\hline $\begin{array}{l}460-519 \\
\text { External causes: }\end{array}$ & 1 & 0.61 & 2 & $1 \cdot 84$ & 3 & $2 \cdot 45$ & $1 \cdot 22$ & $0.25-3.58$ \\
\hline $\begin{array}{l}\text { Accidents 800-944 } \\
\text { Other 950-998 } \\
\text { All other }\end{array}$ & $\begin{array}{l}2 \\
0 \\
1\end{array}$ & $\begin{array}{l}0.81 \\
0.72 \\
2 \cdot 00\end{array}$ & $\begin{array}{l}2 \\
3 \\
5\end{array}$ & $\begin{array}{l}2 \cdot 59 \\
1 \cdot 36 \\
4 \cdot 24\end{array}$ & $\begin{array}{l}4 \\
3 \\
6\end{array}$ & $\begin{array}{l}3 \cdot 40 \\
2 \cdot 08 \\
6 \cdot 24\end{array}$ & $\begin{array}{l}1 \cdot 18 \\
1 \cdot 44 \\
0 \cdot 96\end{array}$ & $\begin{array}{l}0 \cdot 32-3 \cdot 01 \\
0 \cdot 30-4 \cdot 22 \\
0 \cdot 35-2 \cdot 09\end{array}$ \\
\hline
\end{tabular}


Table 7 Observed and expected deaths from respiratory cancer (ICD 160-163) by cumulative exposure (blacks and whites combined)

\begin{tabular}{llllll}
\hline \multirow{2}{*}{$\begin{array}{l}\text { Time from first } \\
\text { employment }(y)\end{array}$} & \multicolumn{5}{c}{ Cumulative exposure $(f / m l y)$} \\
\cline { 2 - 4 } & & $<l$ & $l-<10$ & $\geqslant 10$ & All \\
\hline$<20$ & O & 1 & 1 & 0 & 2 \\
& E & 1.01 & 0.68 & 0.07 & $1 \cdot 76$ \\
20 & O & 2 & 0 & 0 & 2 \\
All & E & 0.74 & 0.69 & $0 \cdot 12$ & 1.54 \\
& O & 3 & 1 & 0 & 4 \\
& E & 1.75 & 1.37 & 0.19 & 3.3 \\
\hline
\end{tabular}

two had typical ferruginous bodies (one and five per pellet). Mean cumulative exposure of workers with typical or atypical bodies in sputum was slightly higher than that of the whole group $(1.3 v 0.9 \mathrm{f} / \mathrm{ml} \mathrm{y}) ;$ the man with five typical bodies per pellet had been employed for 17 years in dusty jobs such as mill cleaner, railcar loader, and millwright, with an estimated exposure of $7 \cdot 3 \mathrm{f} / \mathrm{ml} \mathrm{y}$.

\section{Discussion}

Our studies of Montana vermiculite production in 1983-4 showed substantial risks of respiratory cancer, mesothelioma, and pulmonary fibrosis. ${ }^{1-3}$ It seemed reasonable to attribute these effects wholly to the contaminating tremolite fibres and not to the vermiculite dust. Exposure response analyses of the Montana data suggested that the increased risk of respiratory cancer was about $1 \%$ for each fibre year and of small radiographic opacities $(\geqslant 1 / 0)$ between $0.05 \%$ and $0.1 \%$ per fibre year. The existence in South Carolina of vermiculite deposits, reportedly low in tremolite contamination, afforded the opportunity to obtain further information on these questions, though limited by the small number of people ever employed in that industry.

Review of the qualitative and quantitative data available, supplemented by our further environmental studies, confirmed that elongated particles, mainly of tremolite-actinolite and vermiculite, were present in deposited dust and, mainly of tremolite-actinolite and iron rich material, in air samples. The airborne fibre concentrations, however, were and probably had been

Table 8 Radiographic changes by age for Enoree employees*

\begin{tabular}{llllll}
\hline $\begin{array}{l}\text { Age } \\
\text { (years) }\end{array}$ & No & $\begin{array}{l}\text { Mean } \\
\text { cumulative Small } \\
\text { exposure } \\
(\text { flmly })\end{array}$ & $\begin{array}{l}\text { Pleural } \\
\text { opacities } \\
\text { thickening } \\
\text { (chest }\end{array}$ & $\begin{array}{l}\text { (1/0) } \\
\text { wall) }\end{array}$ & $\begin{array}{l}\text { Pleural } \\
\text { calcification }\end{array}$ \\
\hline $20-39$ & 38 & 0.45 & 0 & 2 & 0 \\
$40-59$ & 35 & $1 \cdot 20$ & 3 & 3 & 0 \\
$\geqslant 60$ & 13 & 3.53 & 1 & 2 & 0 \\
All & 86 & 0.97 & 4 & 7 & 0 \\
\hline
\end{tabular}

*Including the three men whose radiographs were not classified by three readers in the main survey.

Age (years) and cumulative exposure (f/ml y) of the four workers with small opacities $\geqslant 1 / 0(48-0 \cdot 54)(57-6 \cdot 55)(66-3 \cdot 6)(54-2 \cdot 06)$. low. Whereas, in Montana the mean cumulative exposure of the mortality cohort was estimated at $144.6 \mathrm{f} / \mathrm{ml} \mathrm{y}$, the comparable figure was $0.75 \mathrm{f} / \mathrm{ml} \mathrm{y}$ in South Carolina. Similarly, in the radiographic surveys the mean exposure in the Montana subjects was 65.9 $\mathrm{f} / \mathrm{ml} \mathrm{y}$ and $1.0 \mathrm{f} / \mathrm{ml} \mathrm{y}$ in South Carolina. If the risk estimates obtained in Montana were approximately correct no detectable excess of disease would be expected in South Carolina. Bearing in mind limits imposed by the small number of subjects for study, our findings bore out this expectation.

In Montana we introduced for the first time the measurement of typical ferruginous bodies in sputum as a biological method of estimating cumulative exposure. ${ }^{7}$ The results showed a promising correlation between the ferruginous body counts and environmental estimates and evidence that the former discriminated between employees with and without radiographic changes better than the latter. Sputum testing was also undertaken in South Carolina with results that helped to confirm our estimates of low past exposure to fibres. The considerable potential of this method in occupational epidemiology warrants the fullest investigation under varied conditions of exposure.

This research was supported by a grant to McGill University from W R Grace \& Co with whose help subjects were identified for study and past exposures estimated. The chest films were read by $\mathrm{Dr} \mathbf{J}$ Gilson, Dr R Jones, and Dr G Sheers; statistical advice was given by Dr B Armstrong. The active participation of company employees, in particular $\mathrm{Mr} \mathrm{A} \mathrm{H} \mathrm{Skardon}$ and $\mathrm{MrO}$ F Stewart, is gratefully acknowledged.

\section{References}

1 McDonald JC, McDonald AD, Armstrong B, Sébastien P. Cohort study of mortality of vermiculite miners exposed to tremolite. $\mathrm{Br}$ J Ind Med 1986;43:436-44.

2 McDonald JC, Sébastien P, Armstrong B. Radiological survey of past and present vermiculite miners exposed to tremolite. $\mathrm{Br} J$ Ind Med 1986;43:445-9.

3 Amandus HE, Wheeler $R$. Morbidity and mortality of vermiculite miners and millers exposed to tremolite-actinolite. Part II: Mortality. Am J Ind Med 1987;11:15-26.

4 Courbon P, Fabries JF, Wrobel R. Dust measurement on work sites: the CIP 10 dust sampler. In: Liu BYH, Piu DYH, Fissan $\mathrm{HJ}$, eds. Proceedings of the 1st International aerosol conference, Minneapolis, 1984. New York: Elsevier, 1984:521-4.

5 Sébastien P, Gaudichet A, Billon-Galland MA, Janson X. Spectrométrie $\mathrm{X}$ par dispersion d'énrergie en microscopie électronique à transmission: application à la caractérisation des fibres minérales. Journal de Microscopie et de Spectroscopic Electronique 1980;5:83-97.

6 Sébastien P. Measuring asbestos dust in the environment. In: Asbestos, its health risks, analysis, regulation and control. Pittsburgh: Air Pollution Control Association, 1987:97-108.

7 Sébastien P, Armstrong B, Case B, McDonald JC. Estimation of amphibole exposure from asbestos body and macrophage counts in sputum: a survey in vermiculite miners. Ann Occup Hyg (in press).

8 Monson R. Analysis of relative survival and proportional mortality. Computers and Biomedical Research 1974;7:325-32. 